Kristina KILIKEVIČIENĖ

Jonas SKEIVALAS

Artūras KILIKEVIČIUS

Robertas PEČELIŪNAS

Gintautas BUREIKA

\title{
THE ANALYSIS OF BUS AIR SPRING CONDITION INFLUENCE UPON THE VIBRATION SIGNALS AT BUS FRAME
}

\section{ANALIZA WPŁYWU STANU TECHNICZNEGO RESORA PNEUMATYCZNEGO AUTOBUSU NA SYGNAtY DRGAŃ W RAMIE AUTOBUSU}

\begin{abstract}
The paper analyses the spread of vibration intensity through the bus frame mechanical structure. The research has been completed upon application of the theory of covariance functions. Results of measuring the intensity of vibrations at fixed bus framepoints were recorded on the time scale in the form of data arrays (matrixes). The authors have completed the estimation of covariance functions by measuring the intensity of vibrations between the arrays of digital results and auto-covariance functions of single arrays upon changing the quantization interval on the time scale. The research results enable to define if the solidity of bus frame is disordered and to assess the technical condition of pneumatic suspension considering the vibration of frame points. Dangerous zones of bus suspension and reliability level of bus exploitation can be determined by application of these results.
\end{abstract}

Keywords: pneumatic suspension, covariance function, cross-covariance, quantization interval.

\begin{abstract}
W pracy przeprowadzono analizę rozkładu intensywności drgań w mechanicznej konstrukcji ramy autobusu. Badania prowadzono z zastosowaniem teorii funkcji kowariancji. Wyniki pomiaru intensywności drgań w ustalonych punktach ramy autobusu rejestrowano na skali czasu, w postaci tablic danych (matryc). Funkcje kowariancji obliczano porównując natężenie drgań pomiędzy tablicami wyników cyfrowych, zaś funkcje auto-kowariancji pojedynczych tablic obliczano po zmianie przedziału kwantyzacji $w$ skali czasowej. Wyniki badań pozwalaja na określenie, czy zaburzona została stabilność struktury ramy autobusowej oraz umożliwiają ocenę stanu technicznego zawieszenia pneumatycznego na podstawie drgań w określonych punktach ramy. Wyniki te można wykorzystać do określenia niebezpiecznych stref zawieszenia autobusowego oraz poziomu niezawodności pracy autobusu.
\end{abstract}

Stowa kluczowe: zawieszenie pneumatyczne, funkcja kowariancji, kowariancja wzajemna, przedziat kwantyzacji.

\section{Introduction}

Pneumatic suspension, especially air springs, are widely used in the automotive industry as the main components in suspension systems for buses, because they possess advantages such as a consistent structure, adjustable resilient, continuous controlling of the body bottom level from the ground, reasonable guiding effects and convenience in maintenance. Nevertheless, bus exploitation specialists keep searching for new innovative methods and actions to simplify the technical inspection of bus air spring and body frame solidity. The aim of these investigations is to ensure the reliability and the passenger comfort of transportation by a bus. Reducing the time and cost of the bus entire maintenance is possible by applying a non-destructive testing.

The temporal dependence structure of a stationary stochastic process is characterised by the auto-covariance function, or equivalently by its Fourier transform, the spectral density function. Data reconciliation, first introduced by Kuehn and Davidson [10], is a model based filtering method that applies simple process models to improve the reliability and precision of measured variables. Under favourable observation conditions, data reconciliation also allow the estimation of unmeasured process variables. These abilities are valuable for process industries since in many practical cases strategic variables are only measured with limited precision or simply not measured because of technical or economic constraints. Data reconciliation has been ap- plied to a large number of processes as summarized by Mah [11], Narasimhan and Jordache [12]. Other topics are related to data reconciliation, such as sampling error and reconciliation criterion weighing factor evaluation [15], reconciled value accuracy evaluation [6], use of reconciled values to calculate and display plant performance indices, such as concentrate grade and recovery.

The reconciliation of process measurements subject to linear constraints involves finding the minimum weighted sum of squares of adjustments to the measurements. Linear data reconciliation by maximizing the information entropy to obtain probability distributions of the data with the minimum incorporation of prior knowledge was reformulated in the paper [3]. Two cases are presented, first with only the bounds on the data being specified and second with the variancecovariance matrix of the data being specified additionally. The first case provides a means of performing data reconciliation in the absence of information on the variance-covariance matrix of the data. In the second case, reconciliation using maximum likelihood is formally identical to the conventional least-squares solution. The leastprejudiced probability distribution is a truncated normal distribution, which for reasonably precise data essentially coincides with the multivariate normal distribution.

Different data reconciliation techniques have been proposed on the basis of various assumptions concerned with the process dynam- 
ics and depending on the subsequent application of the reconciled data. Steady-state data reconciliation is largely used to estimate the underlying average regime of a plant in applications such as reduction accounting, on process audit, or survey analysis. On the other hand, advanced process control, fault detection algorithms, and real-time optimization require the estimation of true dynamic states of a process, and are generally coupled to dynamic data reconciliation. Different approaches could be taken for dynamic data reconciliation. The filtering algorithm complexity depends on the selected process model. It could range from a simple mass conservation constraint sub-model to a complete causal dynamic model. The selection of the most appropriate algorithm results in a compromise between modelling efforts, required to develop and adapt the observer and improvement of estimate precision.

Researchers Puigjaner and Heyen have discussed the properties of steady-state observers and related problems such as steady-state detection, observation and redundancy analysis, as well as gross error detection [13].Researchers Poulin, Hodouin, and Lachance have studied steady-state data reconciliation applied on a real-time basis [14]. They have concluded that, despite the attractive simplicity of this solution, the estimate precision could be less than measurement precision itself depending on plant dynamics, which is not acceptable from practical point of view. Authors Vasebi, Poulin and Hodouin have proposed a modified stationary observer that takes advantage of the correlation of node imbalances to improve estimation performances [19].

Wavelet analysis has recently been recognized as a tool for important applications in time series, function estimation and image analysis. According to the development of recent wavelet methods, the fundamentals are not yet widely understood, and the guidance on their practical application is hard to find. Wavelets are an increasingly and widely used tool in many applications of signal and image processing. Applications in remote sensing include the combination of images of different resolutions, image compression, and the provision of edge detection methods. Researcher Horgan has reviewed the basic ideas of wavelets in order to represent the information in signals such as time series and images and described how the wavelet shrinkage is applied to smooth these signals [7]. This was illustrated by the application to a synthetic aperture radar image.

Researchers Ekstrom and McEwen have developed adaptive boxfiltering algorithms to remove random bit errors (pixel values with no relation to the image scene) and smooth noisy data (pixels related to the image scene but with an additive or multiplicative noise component[5]. For both procedures they used the standard deviation of those pixels within a local box surrounding each pixel, hence they are adaptive filters. This technique effectively reduced speckle in radar images without eliminating fine details.

Cartographic compilation requires precision mensuration. The calibration of mensuration processes is based on the specific fiducial. External fiducial, around the exterior frame of the image, should be precisely measured to establish the overall sensor geometry [8]. Pre-marked ground points should be provided within the image ofa precise location of panels. Both types of registration marks must be known within the pixel space of a digitized image in order to be accurate with the feature extraction process with regards to delineated features. Classical mensuration of these targets requires that a photogrammetric view the image on a display and use pointing devices, such as a mouse, to pick exact points

Researchers Buchacz et al have decided to solve damping of vibration problems using piezo-electric sensors [2]. Siljak and Subasi investigated Fourier spectrum related properties of vibration signals in accelerated motor aging applicable for age determination[15]. Scientist Kosobudzki applied models to describe the way of loading in frequency domain, he proposed a new model for tracking loading of an element within the under-frame of high mobility wheeled vehicle [9].
The paper analyses the bus frame vibration digital signal estimates carried out upon application of random function theory.

\section{A covariance model of vibration signal parameters}

The theoretical model is based on the conception of a stationary random function while taking into account that errors of measuring the vibration parameters are random and of the same accuracy, i. e. the average error, the dispersion and covariance function of digital signals depends on difference between the arguments, i. e. on the quantization interval on the time scale.

For a theoretical model, we assumed that errors in measuring the intensity of digital signals of vibration field are random. In each column of the array of measuring the intensity of the vibration field, the trend of the measuring data of the column is eliminated. The interval of electromagnetic spread is used as one of the parameters.

We considered the random function (formed according to the arrays of measuring the intensity of the vibration field) as a stationary

function (in a broad sense), i.e. its average value $M\{\phi(t)\} \rightarrow$ const, and covariance function depend only on the difference of arguments $-K_{\phi}(\tau)$. The auto-covariance function of a single data array, or the cross-covariance function of two data arrays $K_{\phi}(\tau)$ is given below[17]:

$$
K_{\phi}(\tau)=\frac{1}{T-\tau} \int_{0}^{T-\tau} \delta \phi_{1}(u) \delta \phi_{2}(u+\tau) d u
$$

where, $\delta \phi_{1}(u), \delta \phi_{1}(u+\tau)$ - the centred values of vibration intensity measurements, $u$ - vibration parameter, $\tau=k \cdot \Delta$ - variable quantization interval, $k$ - the number of measurement units, $\Delta-$ the value of a unit of measurement, $T$ - time.

According to the available data on measurements of vibration parameters, the estimate $K_{\phi}^{\prime}(\tau)$ of covariance function is calculated as follows:

$$
K_{\phi}^{\prime}(\tau)=K_{\phi}^{\prime}(k)=\frac{1}{n-k} \sum_{i=1}^{n-k} \delta \phi_{1}\left(u_{i}\right) \delta \phi_{2}\left(u_{i+k}\right)
$$

where $n$ - total number of discrete intervals.

Formula (2) may be applied in theform of an auto-covariance function or a cross-covariance function. When the function is an auto-

covariance one, the arrays $\phi_{1}(u)$ and $\phi_{2}(u+\tau)$ are parts of single arrays, whilethey are two different arrays in case the function is a cross-covariance one.

The estimate of a normed covariance function is given below:

$$
R_{\phi}^{\prime}(k)=\frac{K_{\phi}^{\prime}(k)}{K_{\phi}^{\prime}(0)}=\frac{K_{\phi}^{\prime}(k)}{\sigma_{\phi}^{\prime 2}}
$$

where $\sigma_{\phi}^{\prime}$ - the estimate of the standard deviation of a random function.

For elimination of the trends of columns in the $i$-th digital array of measurements, the following formulas are applied:

$$
\delta \phi_{i}=\phi_{i}-e \cdot \bar{\phi}_{i}^{T}=\left(\delta \phi_{i 1}, \ldots, \delta \phi_{i m}\right)
$$


where $\delta \phi_{i}$ - the $i$-th digital array of reduced values where a trend of column is eliminated; $\phi_{i}-$ the $i$-th array of the vibration intensity, $e$ - a unit vector of the size $(n \times 1) ; n$ - the number of lines in the $i$-th array, $\overline{\phi_{i}}$ - the vector of average values of columns in the $i$-th array, $\delta \phi_{i j}$ - the j-th column (vector) of the reduced values in the $i$-th array.

The vector of average values of columns in the $i$-th array is calculated according to the following formula:

$$
\bar{\phi}_{i}^{T}=\frac{1}{n} e^{T} \cdot \phi_{i}=\frac{1}{n} \phi_{i}^{T} \cdot e .
$$

A realization of the random function of the $j$-th column of the $i$-th array of vibration intensity in form of vectors is expressed as follows

$$
\delta \phi_{i j}=\left(\delta \phi_{i j, 1}, \ldots, \delta \phi_{i j, m}\right) .
$$

The estimation of the covariance matrix of the $i$-th array of wavelet intensity is expressed as follows:

$$
K^{\prime}\left(\delta \phi_{i}\right)=\frac{1}{n-1} \delta \phi_{i}^{T} \delta \phi_{i}
$$

The estimation of covariance matrix of two arrays of vibration intensity is written as follows:

$$
K^{\prime}\left(\delta \phi_{i}, \delta \phi_{j}\right)=\frac{1}{n-1} \delta \phi_{i}^{T} \delta \phi_{j}
$$

where the sizes of $\delta \phi_{i}, \delta \phi_{j}$ arrays should be the same.

The estimates $K^{\prime}\left(\delta \phi_{i}\right)$ and $K^{\prime}\left(\delta \phi_{i}, \delta \phi_{j}\right)$ of covariance matrixes are reduced into estimates of matrixes of correlation coefficients

$$
\begin{aligned}
R^{\prime}\left(\delta \phi_{i}\right) \text { and } R^{\prime}\left(\delta \phi_{i}, \delta \phi_{j}\right) & {[18]: } \\
R^{\prime}\left(\delta \phi_{i}\right) & =D_{i}^{-1 / 2} K^{\prime}\left(\delta \phi_{i}\right) D_{i}^{-1 / 2}, \\
R^{\prime}\left(\delta \phi_{i}, \delta \phi_{j}\right) & =D_{i j}^{-1 / 2} K^{\prime}\left(\delta \phi_{i}, \delta \phi_{j}\right) D_{i j}^{-1 / 2},
\end{aligned}
$$

where $D_{i}, D_{i j}$ - the diagonal matrixes of members of principal diagonals in the estimates of covariance matrixes $K^{\prime}\left(\delta \phi_{i}\right)$ and $K^{\prime}\left(\delta \phi_{i}, \delta \phi_{j}\right)$, respectively.

The accuracy of the calculated coefficients of correlation is defined by the standard deviation $\sigma_{r}$, and the value of the latter is assessed according to the following formula:

$$
\sigma_{r}=\frac{1}{\sqrt{n}}\left(1-r^{2}\right)
$$

where $n=8000, r$ - coefficient of correlation. The maximum value of the standard deviation is obtained when the value of $r$ is close to zero and in this case $\sigma_{r}^{\prime} \approx 0.01$; when $r \approx 0.5$ we obtain $\sigma_{r}^{\prime} \approx 0.008$.

Estimates of the covariance functions of digital arrays of two vibration signals or the covariance functions of a single array are calculated upon transformation of the digital arrays into vectors. For processing the digital signals, discrete Fourier transform and the theory of wavelet functions were applied.

\section{Results of the experiment and research}

The data arrays of measuring the relevant parameters of vibration signals were formed in measuring vibrations of a bus body at certain points upon using vibration measuring and data processing „Bruel and Kjear"equipment (Fig. 1, side a) and seismic accelerometers 8344(Fig. 1, side b).

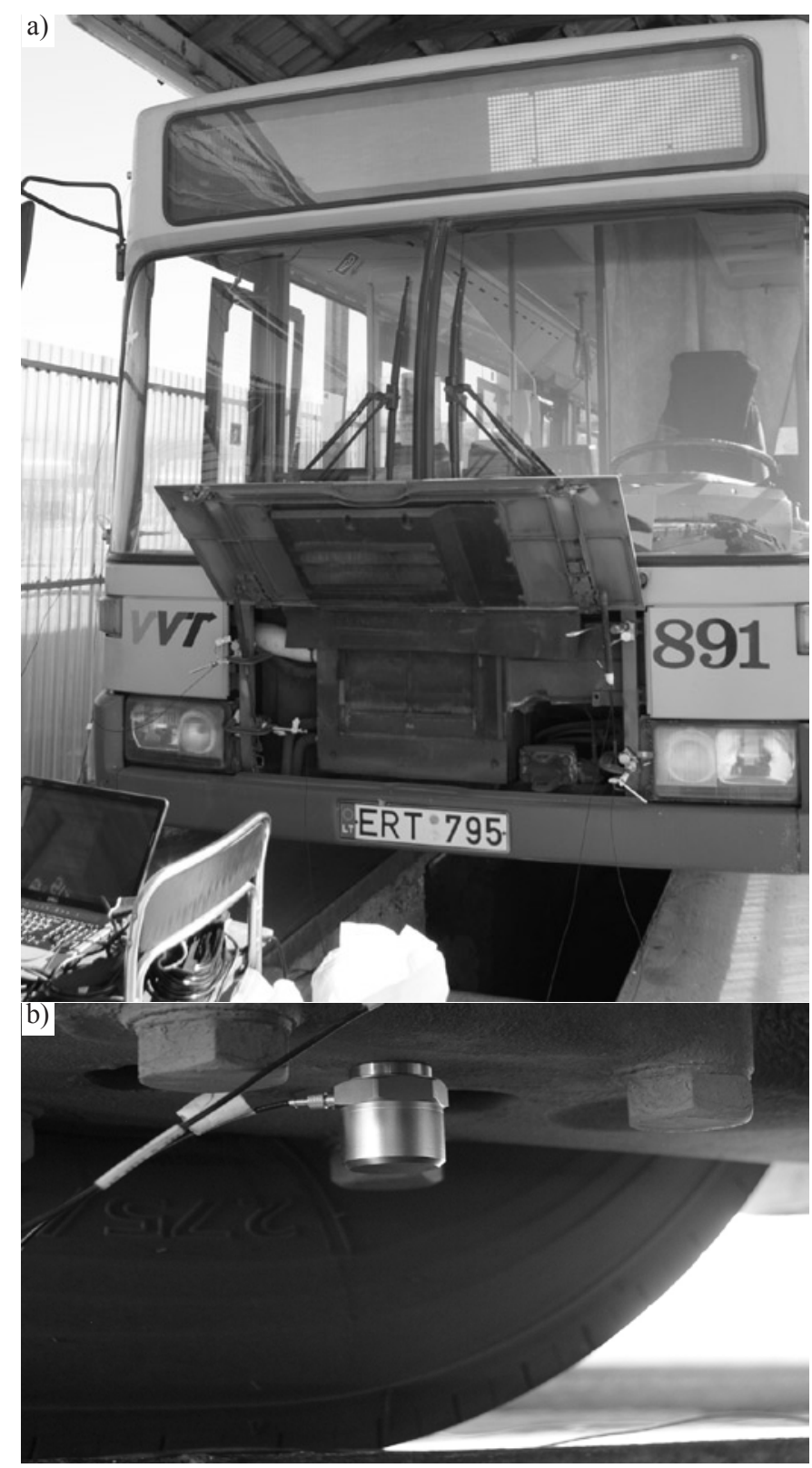

Fig. 1. The measuring equipment of vibration parameters: a) portable measurement data: processing, storage and control equipment ,,3660-D“ with DELL computer; b) accelerometer 8344.

Vectors of vibration signals were measured at the fixed points of the bus body and measurement data arrays of 4 vectors were obtained for each of two states. The signals were fixed in the interval $\tau_{\Delta}=2,44140630 \cdot 10^{-4} \mathrm{~s}$ for $4.0 \mathrm{~s}$. Each vector of an array included $n=16386$ values of vibration signals.

Vibrations were measured at certain points of the bus body frame and suspension air springs (shown in Fig. 2) in quiescent state (i.e. 
when the bus was not affected by external excitation), on starting the engine and upon shock excitation. The measurements were carried out in avertical position. The views of the measurement points are provided in Fig. 3. The measurement results are presented in Fig. 4, Fig. 5 and Fig. 6.

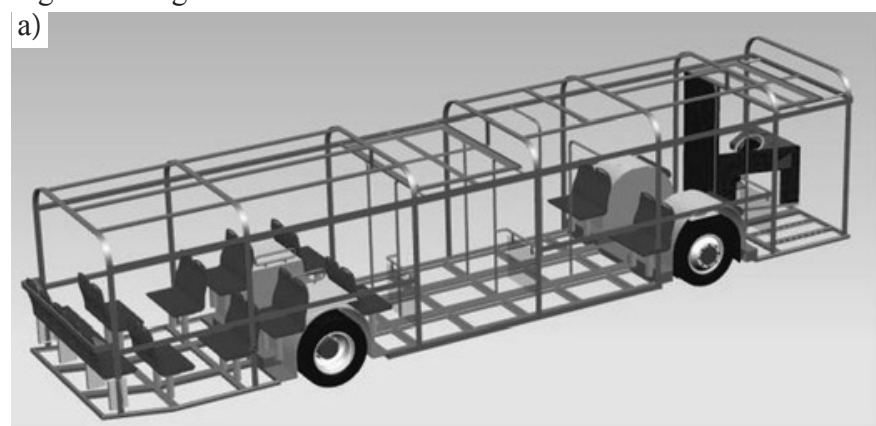

b)

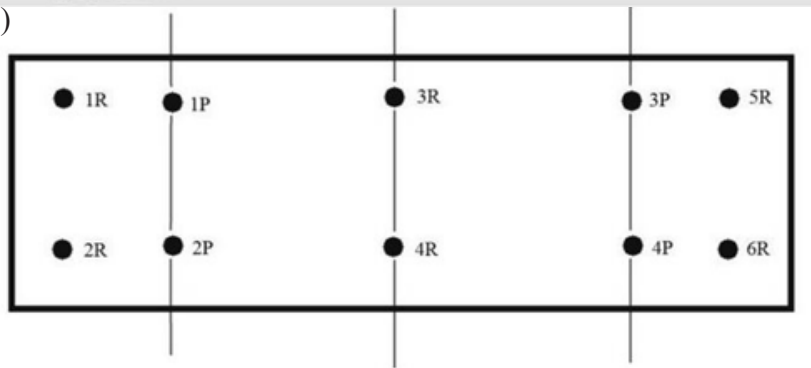

Fig. 2. The scheme of bus frame and pneumatic suspension vibration measurement points: a) the view of the body frame; b) the bottom view
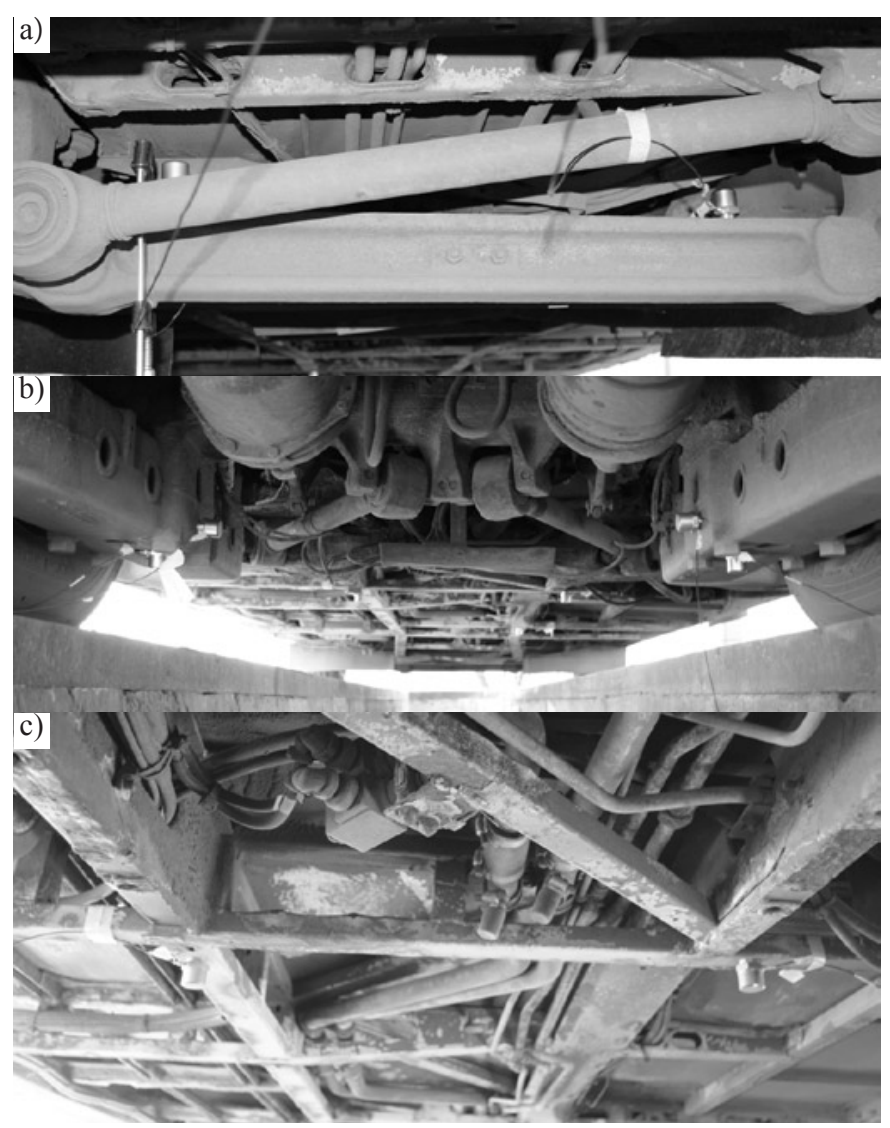

Fig. 3. The bus body frame and pneumatic suspension vibration measurement points: a) the points of the front suspension of the bus (Fig. 2, IP and $2 P$ ); $b$ ) the points of the frame in the middle of the bus (Fig. 2, 3R and $4 R$ ); c) the points of the rear suspension of the bus (Fig. 2, 3P and 4P)

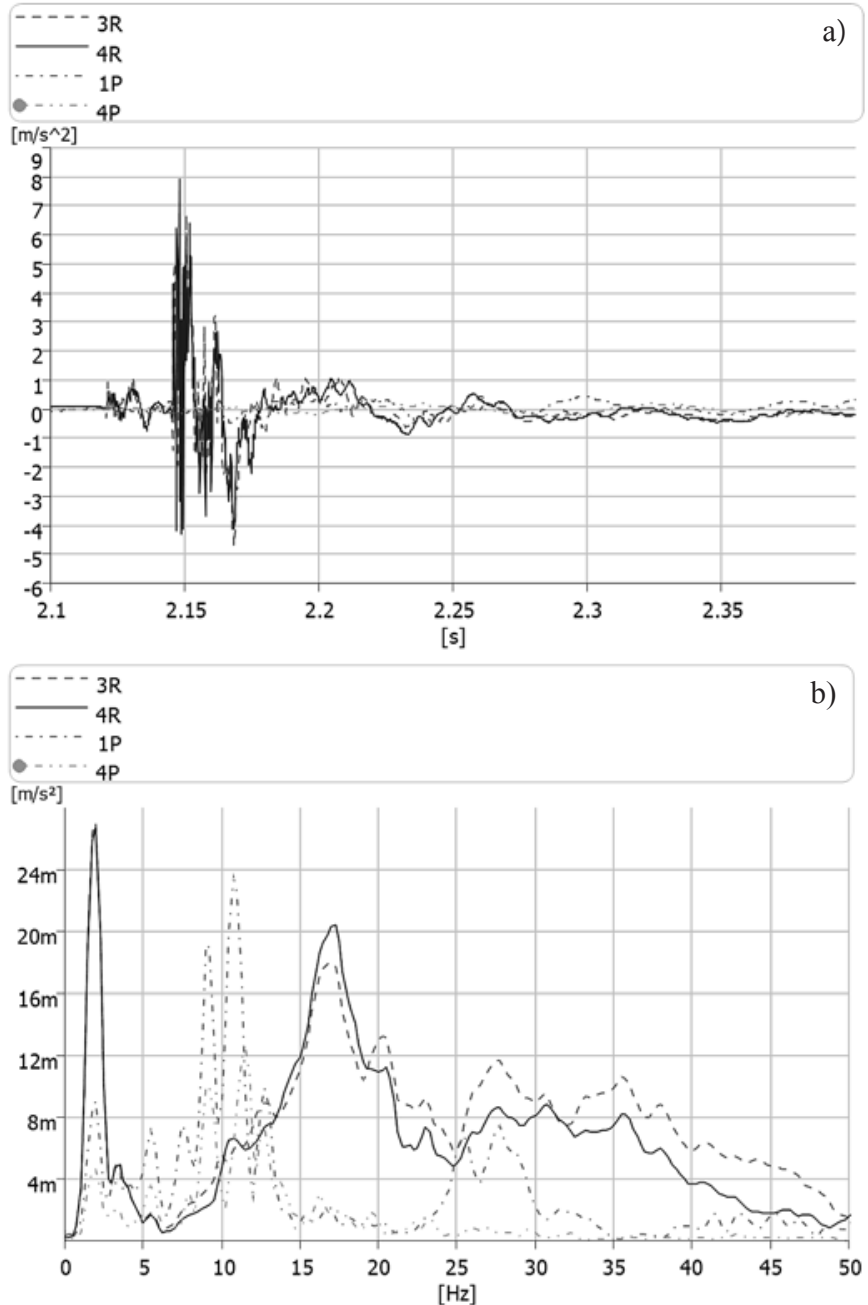

Fig. 4. The diagrams of time signal of absolute vibration vertical acceleration amplitude in the middle points of the frame (a) (Fig. 2 above, the points $3 R$ and $4 R$ ) and the pneumatic suspension (b) (Fig. 2 above, the points $1 P$ and $4 P$ ) upon shock excitation of the bus body centre (air pressure of $6.5 \mathrm{MPa}$ ).

$\begin{array}{ll}\cdots & 3 R \\ \cdots \cdots & 4 R \\ {\left[\mathrm{~m} / \mathrm{s}^{\wedge} 2\right]} & 4 P\end{array}$

$\left[\mathrm{m} / \mathrm{s}^{\wedge}\right.$

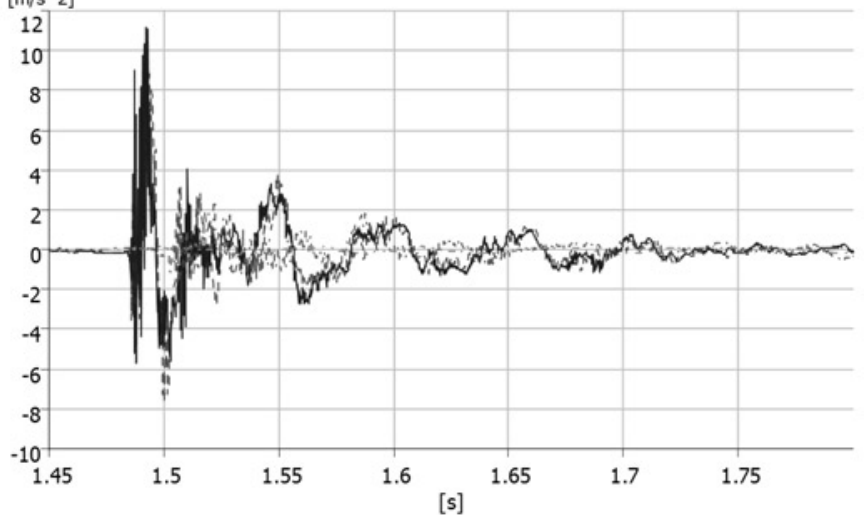

Fig. $5 a$.

The obtained results (Fig. 4 and Fig. 5 above) show that the air pressure increased by $1.5 \mathrm{MPa}$ in the air springs causes reduction of the values of frequencies that correspond to the dominating amplitudes of acceleration on the frequency diagram from $2 ; 3.5 ; 5.5 ; 7.5$; 


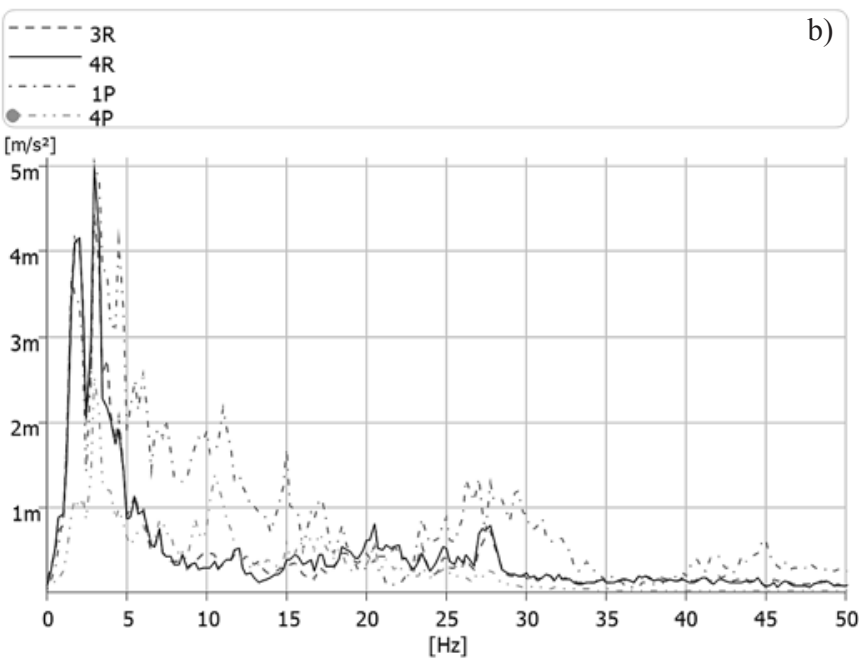

Fig. 5b. The diagrams of time signal of absolute vibration vertical acceleration amplitude in the middle points of the frame (a) (Fig. 2 above, the points $3 R$ and 4R) and the pneumatic suspension (b) (Fig. 2 above, the points $I P$ and $4 P$ ) upon shock excitation of the bus body centre(air pressure of $6.5 \mathrm{MPa}$ ).

$9.0 ; 10.75 ; 11.5 ; 12.75$ and $17 \mathrm{~Hz}$ (at air pressure of $6.5 \mathrm{MPa}$ ) to 1.75 ; $3.0 ; 4.5 ; 5.5 ; 6.0 ; 9.25 ; 10.5 ; 11$ and $15 \mathrm{~Hz}$ (at air pressure of $8 \mathrm{MPa}$ ).

A shock excitation have been applied for the measurements of vibration of the mechanical construction of the bus with air springs. Upon the first condition, the air pressure in the air springs was 6.5 $\mathrm{MPa}$. Upon the second condition, the air pressure in the air springs was 8.0 MPa. For each condition, the measurements were carried out at four points of the bus frame (3R, 4R, 1P, 4P) and a vector of the measurement results was obtained for each point. Thus, four measurement vectors were obtained for each condition. In order to simplify numbering of these vectors the sequence numeration $(1,2,3,4)$ was applied in the calculation. The vectors of both conditions were integrated into one system and vectors were numbered $(1,2,3,4 ; 5,6,7,8)$.

The arrays of the measuring data were processed according to the developed software upon applying operators of Matlab 7 program package.

The values of quantization intervals of the normed covariance functions vary from 1 to $n / 2$, were - the number of lines (values) of the wavelet signal vector in an array. An array of measuring wavelet signals consists of 4 vectors (columns), were each point of the bridge surface corresponds to one vector of measuring results. For each vector, the estimate $K_{\varphi}^{\prime}(\tau)$ of the normed covariance function $K_{\varphi}(\tau)$

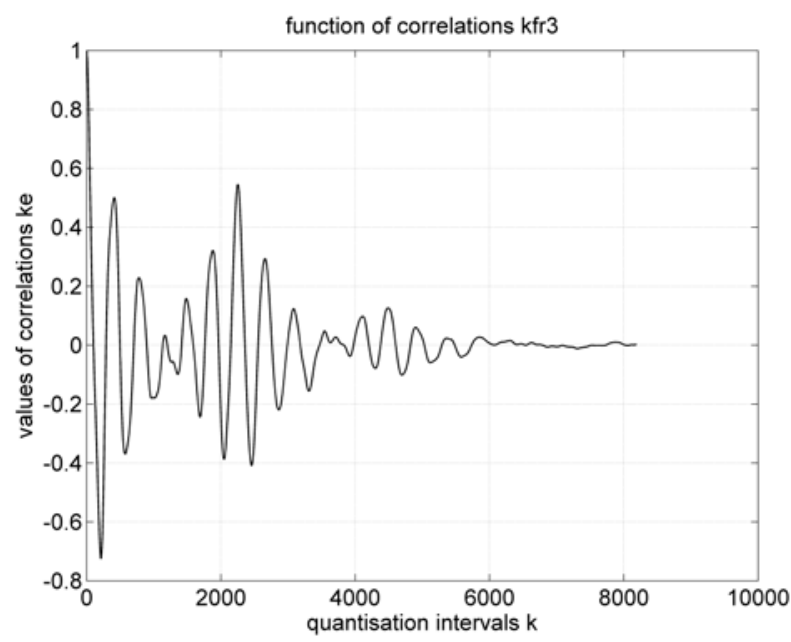

Fig. 6. The normed auto-covariance function of the vibration signals at the point $1 P$ when the bus engine is off

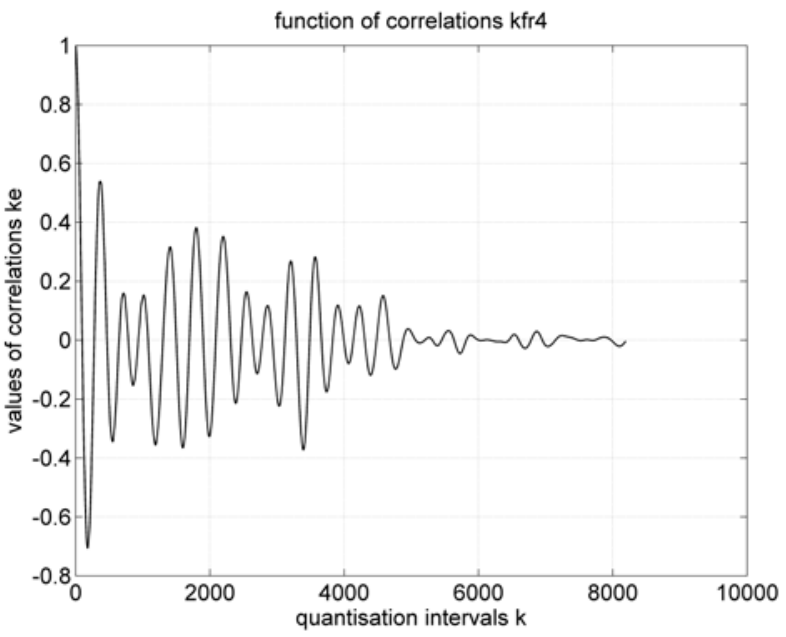

Fig. 7. The normed auto-covariance function of the vibration signals at the point $4 P$ when the bus engine is off

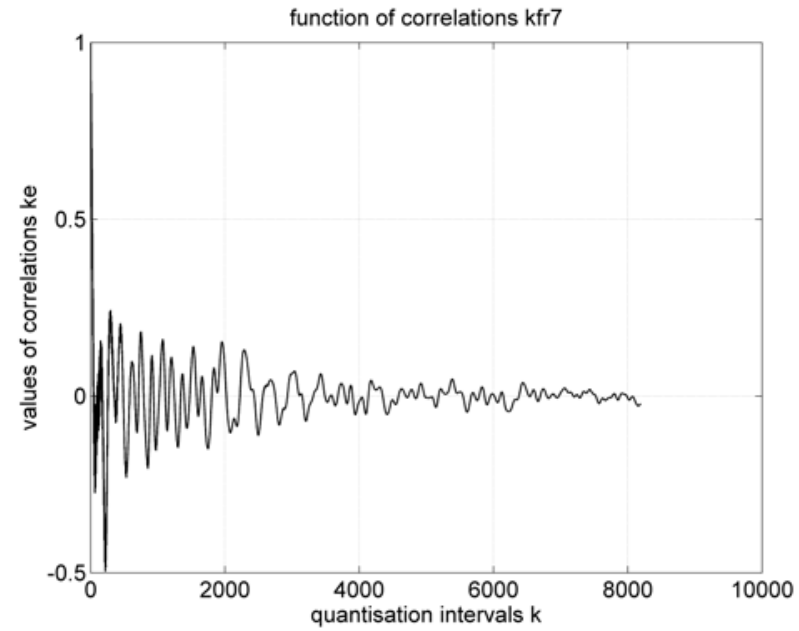

Fig. 8. The normed auto-covariance function of the vibration signals at the point $1 P$ when the engine is in operating mode

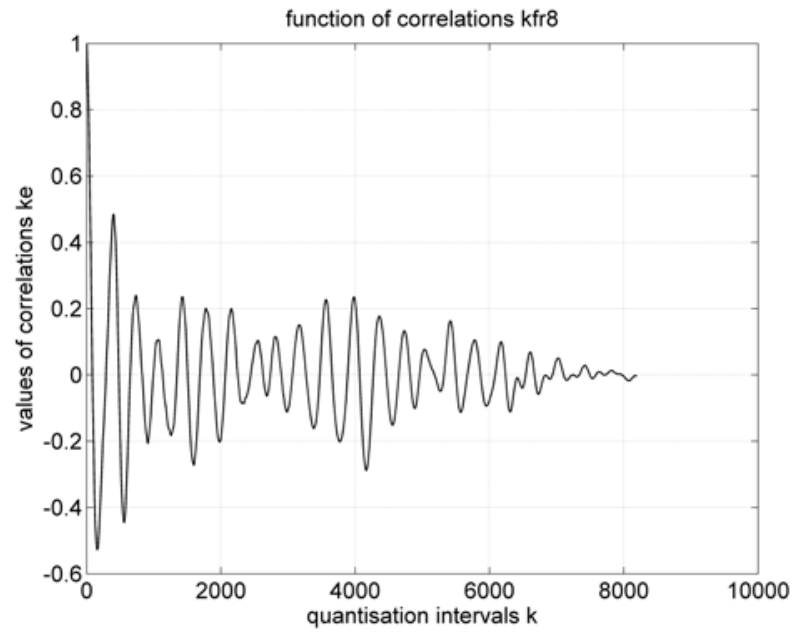

Fig. 9. The normed auto-covariance function of the vibration signals at the point $4 P$ when the engine is in operating mode

was calculated and 6 graphical expressions of the normed covariance functions were obtained. In addition, the estimate of the normed crosscovariance functions $K_{\varphi}^{\prime}(\tau)$ according to the vectors of all 4 points and 6 graphical expressions was obtained. 


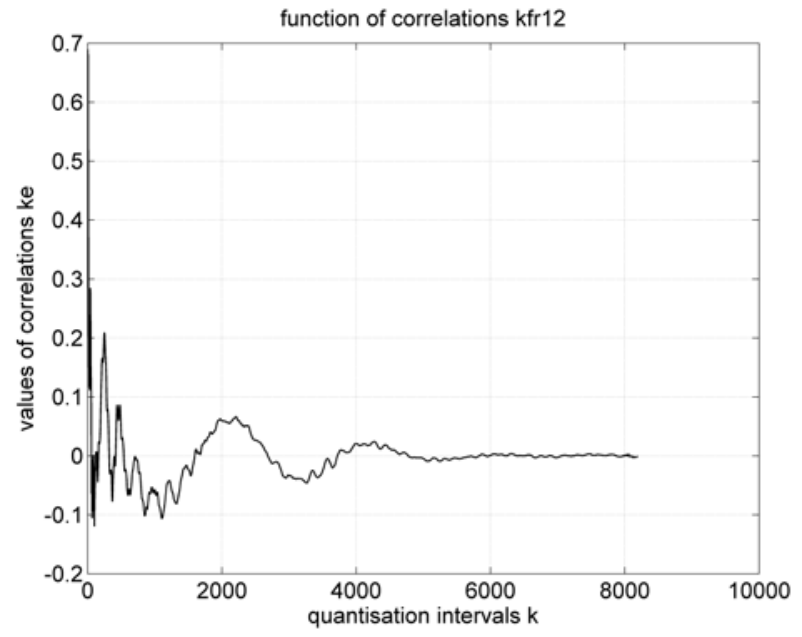

Fig. 10. The normed cross-covariance function of the vibration signals at the points $3 R$ and $4 R$ when the bus engine is off

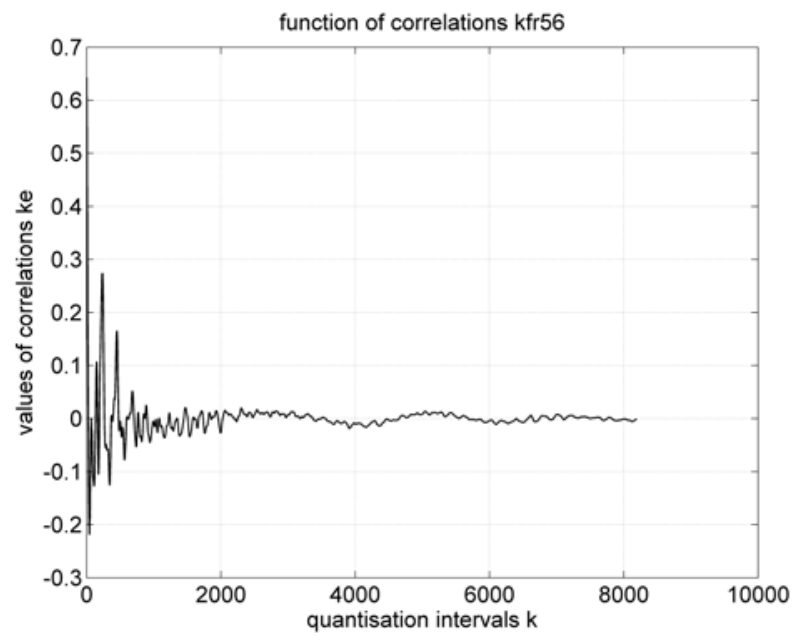

Fig. 12. The normed cross-covariance function of the vibration signals at the points $3 R$ and $4 R$ when engine is in operating mode

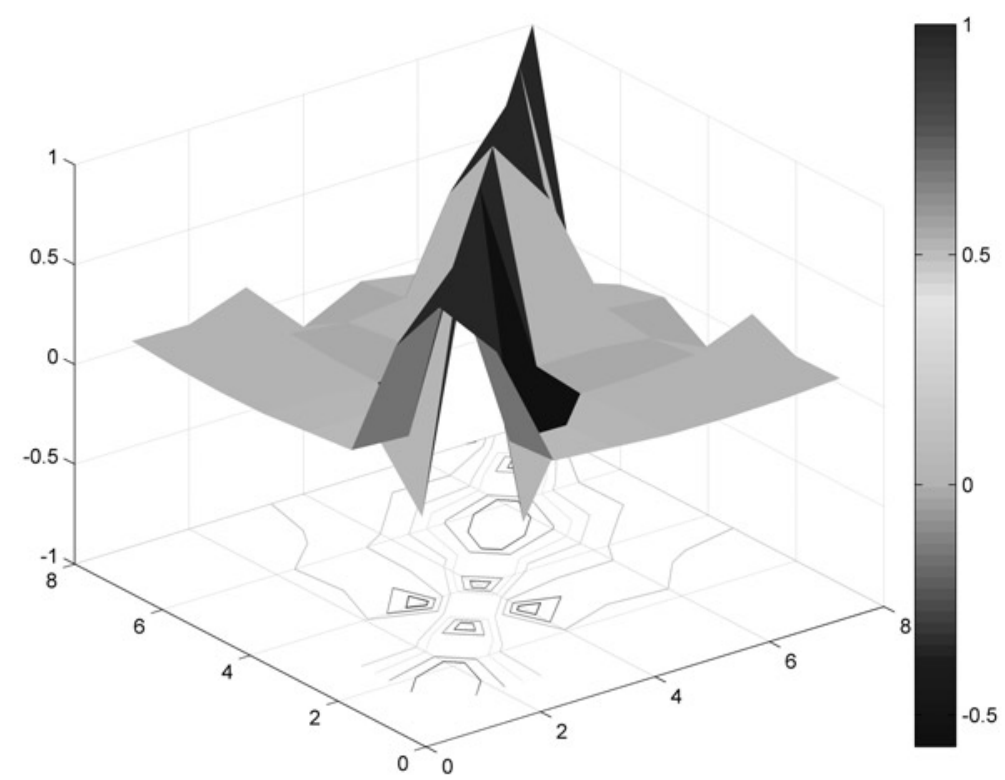

Fig. 13. The graphical expression of the generalized (spatial) correlation matrix of the array of 8 vectors of digital bus body vibration signals

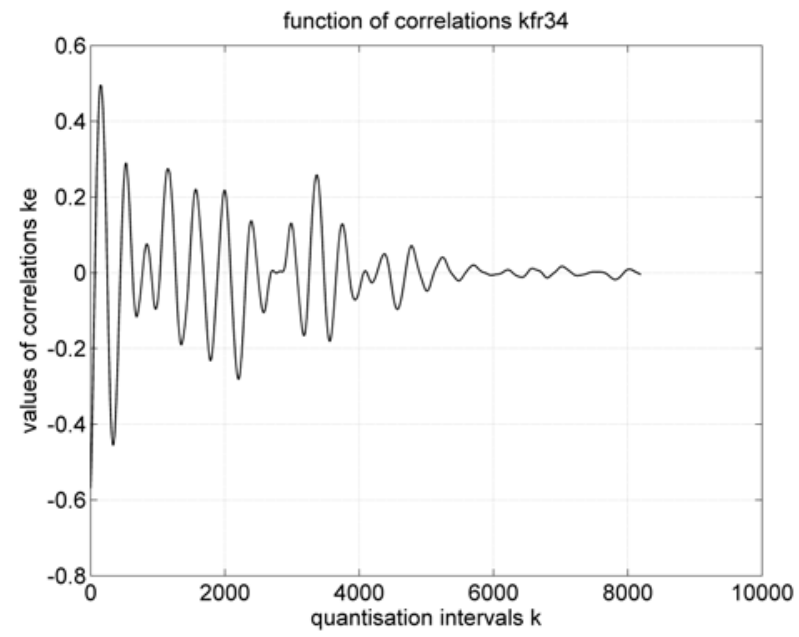

Fig. 11. The normed cross-covariance function of the vibration signals at the points $3 P$ and $4 P$ when bus engine is off

The most important graphical expressions of normed auto-covariance and cross-covariance functions are provided in Fig. 6-12 below.

The graphical view of the generalized correlation matrix of 8-vector array for 4 points of the bus upon two states is presented in Fig. 13. The expression of the correlation matrix turns into a block of 8 pyramids where the values of correlation coefficients are shown as colours of the spectrum. The chromatic projection of the pyramids is shown in the horizontal plane.

The estimates of normed auto-covariance functions and cross-covariance functions are of "damping" character from and they become equal to $0 k \rightarrow 0$ when the number of quantization intervals $k \rightarrow 4000$ or the time intervals $\tau_{k}=k \cdot \tau_{\Delta}=0.98 \mathrm{~s}$

The slower decrease of the estimates of the auto-covariance functions is caused by the vectors $1 \mathrm{P}$ and $4 \mathrm{P}$ upon the both states when $|r| \rightarrow 0.4-0.5$ at $k \rightarrow 4000\left(\tau_{k} \rightarrow 0.98 s\right)-k \rightarrow 7000\left(\tau_{k} \rightarrow 1.7 s\right)$ and they further decrease down to the value close to zero. This shows that "damping" of covariance of vibration signals is slower in the vectors $1 \mathrm{P}$ and $4 \mathrm{P}$ upon the both states.

The estimates of normed cross-covariance functions are close to zero when for all vectors and for all quantization intervals upon the both states, except of vectors with low values of the correlation coefficients between them. They include:

- $3 R$ and $4 R$ (for the state 1 ), when

- $1 \mathrm{P}$ and $4 \mathrm{P}$ (for the state 1 ), when

- $1 \mathrm{P}$ (for the state 1) and 4P (for the state 2), when

- 4P (for the state 1) and 4P (for the state 2), when

- $3 \mathrm{R}$ (for the state 2) and 4P (for the state 2), when

- $3 \mathrm{R}$ (for the state 2) and 4P (for the state 2), when

- $4 \mathrm{R}$ (for the state 2) and 4P (for the state 2), when

It must be stated that the pressure in the bus air spring practically makes no influence on the vibration intensity and correlation.

\section{Conclusions}

1. The normed auto-covariance and cross-covariance functions of vibration signals at the preselected points of the bus body mechanical structure enable to establish the changes of correlation between the data vectors according to the quantization interval on the time scale. The estimates of normed auto-covariance functions "damp" rather quickly when the quantization interval is from 0 to 4000 upon both the states under measurement. Slower "damping" of covariance of vi- 
bration signals takes place in the vectors $1 \mathrm{P}$ and $4 \mathrm{P}$ within both the states.

2. The estimates of the normed cross-covariance functions are close to zero, when $|r| \rightarrow 0$ for all vectors of vibration signals andfor all quantization intervals in upon both states under measurement. The values of several cross-covariance func- tions are higher and vary in the range $|r| \rightarrow 0.2-0.5$. It must be stated that bus air spring pressure variation from $6.5 \mathrm{MPa}$ up to $8.0 \mathrm{MPa}$ practically makes no influence on the vibration intensity and correlation of the bus body.

\section{References}

1. Antoine JP. Wavelet analysis of signals and images. A grand tour, Revista Ciencias Matematicas (La Habana) 2000; 18: 113-143.

2. Buchacz A, Płaczek M, Wróbel A. Modelling of passive vibration damping using piezoelectric transducers - the mathematical model. Eksploatacja i Niezawodnosc - Maintenance and Reliability 2014; 16 (2): 301-306.

3. Crowe CM. Formulation of linear data reconciliation using information theory. Chemical Engineering Science 1996; 51: 3359-3366, http:// dx.doi.org/10.1016/0009-2509(95)00369-X.

4. Dutkay DE, Jorgensen PET. Wavelets on fractals. Rev. Mat. Iberoamericana 2004; 22: 131-180.

5. Ekstrom M, McEwen A. Adaptive box filters for removal of random noise from digital images, Photogrammetric Engineering and Remote Sensing 1990; 56(4): 453-458.

7. Horgan G. Wavelets for SAR image smoothing, Photogrammetric Engineering and Remote Sensing 1998; 64(12): 1171-1177.

8. Hunt B, Ryan TW, Gifford FA. Hough transform extraction of cartographic calibration marks from aerial photography, Photogrammetric Engineering and Remote Sensing 1993; 59(7): 1161-1167.

9. Kosobudzki M. The use of acceleration signal in modeling proces of loading an element of underframe of high mobility wheeled vehicle. Eksploatacja i Niezawodnosc - Maintenance and Reliability 2014; 16 (4): 595-599.

10. Kuehn DR., Davidson H. Computer control II: Mathematics of control. Chemical Engineering Progress 1961; 57: 44-47.

11. Mah RSH. Process data reconciliation and rectification. In Chemical process structures and information flows. Butterworth-Heinemann 1990; 385-466, http://dx.doi.org/10.1016/B978-0-409-90175-7.50014-1.

12. Narasimhan S, Jordache C. Data reconciliation and gross error detection: An intelligent use of process data. Huston: Gulf Publishing Company, 2000.

13. Puigjaner L, Heyen G. Computer aided process and product engineering. Weinheim: Wiley-VCH, 2006, http://dx.doi. org/10.1002/9783527619856.

14. Poulin É, Hodouin D, Lachance L. Impact of plant dynamics on the performance of steady-state data reconciliation. Computers and Chemical Engineering 2010; 34: 354-360, http://dx.doi.org/10.1016/j.compchemeng.2009.11.018.

15. Romagnoli JA., Sanchez MC. Data processing and reconciliation for chemical process operations. San Diego: Academic Press, 2000.

16. Siljak H, Subasi A. Fourier spectrum related properties of vibration signals in accelerated motor aging applicable for age determination. Eksploatacja i Niezawodnosc - Maintenance and Reliability 2014; 16 (4): 616-621.

17. Skeivalas J. Theory and practice of GPS networks. Vilnius: Technika, 2008. [In Lithuanian].

18. Skeivalas J, Aleknienè E, Gečytè S. Analysis of identifying the digital images of the earth's surface. Geodesy and Cartography 2010; 36(4): 146-150. [In Lithuanian], http://dx.doi.org/10.3846/gc.2010.23.

19. Vasebi A, Poulin É, Hodouin, D. Observers for mass and energy balance calculation in metallurgical plants. The 18th IFAC World Congress Milano 28.08.2011-02.09.2011

\section{Kristina KILIKEVIČIENÉ \\ Robertas PEČELIŪNAS}

Department of Automobile Transport

Vilnius Gediminas Technical University

J. Basanavičiaus str. 28, LT-03224 Vilnius, Lithuania

\author{
Jonas SKEIVALAS \\ Dept of Geodesy and Cadastre \\ Vilnius Gediminas Technical University \\ Saulètekio al. 11, LT-10223 Vilnius, Lithuania \\ Artūras KILIKEVIČIUS \\ Department of Mechanical Engineering \\ Vilnius Gediminas Technical University \\ J. Basanavičiaus str. 28, LT-03224 Vilnius, Lithuania
}

\section{Gintautas BUREIKA}

Department of Railway Transport

Vilnius Gediminas Technical University

J. Basanavičiaus str. 28, LT-03224 Vilnius, Lithuania

E-mail: kristina.kilikeviciene@vgtu.It; robertas.peceliunas@vgtu.It jonas.skeivalas@vgtu.It, arturas.kilikevicius@vgtu.It gintautas.bureika@vgtu.lt 